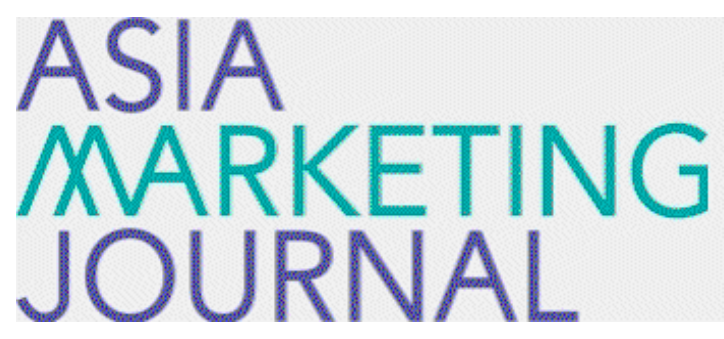

ASIA MARKETING JOURNAL

Volume 21

Issue 2 01/01/2019

Article 4

7-31-2019

\title{
Effect of Online Word of Mouth on Product Sales: Focusing on Communication-Channel Characteristics
}

Jaihyun Jeon

Taewook Lim

Byung-Do Kim

Seok

Follow this and additional works at: https://amj.kma.re.kr/journal

Part of the Marketing Commons

\section{Recommended Citation}

Jeon, Jaihyun; Lim, Taewook; Kim, Byung-Do; and Seok (2019) "Effect of Online Word of Mouth on Product Sales: Focusing on Communication-Channel Characteristics," Asia Marketing Journal: Vol. 21 : Iss. 2 , Article 4.

Available at: https://doi.org/10.15830/amj.2019.21.2.73

This Article is brought to you for free and open access by Asia Marketing Journal. It has been accepted for inclusion in Asia Marketing Journal by an authorized editor of Asia Marketing Journal. 


\title{
Effect of Online Word of Mouth on Product Sales: Focusing on Communication-Channel Characteristics*
}

\author{
Jaihyun Jeon** \\ Taewook Lim*** \\ Byung-Do Kim**** \\ Junhee Seok
}

\begin{abstract}
As information and communication technology continue its remarkable development, the exchange
\end{abstract} of information online becomes as prevalent and frequent as face-to-face communication in daily life. Therefore, the management and application of WOM (word of mouth) practices will become more important than ever to companies. Currently, there are various types of communication channels for online WOM, and each channel has its own unique traits. Most of the previous research studies online WOM by examining the information inside a single communication channel, but this research chooses two different communication channels and analyzes the effects of online WOM with each channel's unique characteristics. More specifically, this research focuses on the expectation that the effects of information from Twitter and blogs on product sales may differ because Twitter and blogs, two different communication channels for online WOM, have their own unique traits. Our particular aim is to perform an in-depth examination on the effects of communication channel's volume and valence on product sales, two important attributes of online WOM. Furthermore, while most of the empirical research focuses on online WOM and analyzes its effect on markets of temporary experience goods, such as movies and books, this research highlights focuses on the automobile market, a durable goods market.

The results of our analysis are as follows: First, regarding blogs, a positive valence significantly and positively affects the sales of products, and this result indicates that consumers are influenced more by the emotional aspect of a product presented in a post than by the number of blog posts. Second, regarding Twitter, the volume of online WOM significantly and positively affects sales, an indication that as the number of posts increase, the sales increase.

\footnotetext{
* This work was supported by the Institute of Industrial Relations, Seoul National University.

** Graduate student, College of Business Administration, Seoul National University (jaihyun92@gmail.com), First Author

*** Graduate student, College of Business Administration, Seoul National University (taewooklim93@gmail.com)

**** Professor, College of Business Administration, Seoul National University (bxk@snu.ac.kr)

***** Ph.D. student, College of Business Administration, Seoul National University (boss825@snu.ac.kr), Corresponding Author
} 
Through this research, we suggest that even those firms that sell durable goods can increase sales through the management and application of online WOM. Moreover, according to the characteristics of communication channels, the effects of online WOM on sales differ. As a practical implication of this research, we suggest that companies can and should create marketing strategies appropriate to their targeted communication channels.

Key words: Word of Mouth, Online Word of Mouth, Twitter, Blogs, Word of Mouth Channels

\section{Introduction}

Personal computers and smart phones are daily necessities these days. At those times when such electronic equipment did not exist, people exchanged information by meeting with each other in person. Now, though, most information exchanges occur online. Consumers tend to gather information before purchasing products, and they do so by searching for other's opinions. For instance, many consumers search for postscripts or expert reviews on certain books. This searching process takes place on social media, a term that includes all social network services (SNS) such as blogs, Facebook, and Twitter. According to Nielsen (2009, 2012), 46\% of online users get help from social media in the process of purchasing products, and $70 \%$ of them mention that they trust recommendations from anonymous users more than advertisements from traditional media, such as those found on television and radio. Statista (2017) found that as of 2017,
$71 \%$ of internet users were using SNS, and it is expected that SNS users will grow to more than three billion by 2021 as electronic devices are continuously developed and supplied. Since the number of social media users tends to continuously increase, social media's power will eventually be greater than that of traditional media. Therefore, the application and management of online WOM will be one of the most important issues to modern firms (Moorman 2014).

With the importance of online WOM finding recognition, numerous researches have been conducted to study the effects of online WOM, especially on effects of volume and valence. Volume refers to the total amount of online WOM, and valence represents the emotional aspect, such as whether the online WOM is positive or negative (Liu 2006). Early research focused on the effect of volume has shown that increasing the volume of online WOM increases brand awareness and decreases consumer anxiety (Chen, Wang, and Xie 2011; Chintagunta, Gopinath, and Venkataraman 2010; Park, Gu, and Lee 2012). Later research studied the 
valence of online WOM. Doh and Hwang (2009) have asserted that negative online WOM negatively affects sales. In the case of positive online WOM, most research has consistently remarked that it positively affects a firm's sales (File and Prince 1992; Lee and Youn 2009). As mentioned, despite numerous studies on online WOM, we recognize several limitations. First, much empirical research is based on temporary experience goods, such as movies and books, and only uses a few online WOM channels. Rosario et al. (2016), which has conducted a meta-analysis of 96 researches on online WOM, has shown that books (39\%) and movies $(20 \%)$ have been the subjects of the research, accounting for more than half of the proportion of online WOM studies. The reason that the subjects of many studies are limited to a few products is because collecting online WOM data on these products is relatively easier than with other products. Second, most studies only gather data from one communication channel of online WOM, and most of it is gathered from either Twitter (Hennig-Thurau, Wiertz, and Feldhaus 2015; Jansen et al. 2009; Jin and Phua 2014) or blog posts (Dewan and Ramprasad 2009; Pal and Kapur 2010; Qin 2011). However, we predict that because online WOM channels each have their own unique characteristics, the effects of online WOM may differ according to each communication channel's characteristics. Third, studies on online WOM with empirical data are quite few.
Because online WOM is like a trading activity for sharing information between consumers, the most efficient way to estimate its effects is to use existing online WOM data. However, since collecting such data is limited by a low number of available methodologies, most studies tend to gather consumer response data through surveys or experiments (Hennig-Thurau, Walsh, and Walsh 2003; File and Prince 1992; Richins 1983).

Compared to existing research, this study has several distinguishing features. First, we examine the role of online WOM in a durable good market, rather than in a market for a temporary experience good. In order to generalize the effect of online WOM, more research focused not only on temporary experience goods but also on other types of goods is required (Chung and Kim 2011; Rosario et al. 2016). We have therefore chosen the automobile market, whose products count as durable goods and have relatively high prices. Second, by using a web text mining program, we analyze the effects of volume and valence, two important attributes of online WOM, in a single model. Third, we evaluate the effect of valence and volume from two different communication channels at the same time, as there are only a few studies that examine the effects of volume and valence from more than two online communication channels simultaneously (Seok, Lee, and Kim 2018). Since there are various types of communication channels for sharing information, 
and because their characteristics differ, we predict that each channel's effect on online WOM may differ, leading us to decide on estimating the effects from two representative channels simultaneously. The rest of this paper proceeds with a literature review in Section 2, outlining some major prior work related to online WOM. We then discuss our estimation methods and describe proposed models in Section 3. In Section 4, we present our empirical findings. We then discuss our conclusion and several implications and limitations.

\section{Literature Review}

\subsection{What is Online Word of Mouth (WOM)?}

WOM can be defined as a communication about a certain product or brand between more than two consumers (Baker, Donthu, and Kumar 2016). As soon as consumers were provided with the online space, a new environment where they could share their opinions, online WOM found expression and began to be used. Online WOM is defined as communication without any restriction, between potentially infinite numbers of online users (Stauss 1997). Online WOM allows consumers to not only directly gather information about certain products and services but also read the opinions of consumers from all over the world (Lee et al. 2006: Ratchford, Talukdar, and Lee 2001). According to Liu (2006), volume and valence are among the most important online WOM attributes that have been examined by numerous papers, with volume indicating the total numbers or amounts of online WOM interactions, and valence capturing the thrust of positivity or negativity, determined by analyzing the emotions behind words within a certain amount of messages. Overall, online WOM is a communication between consumers in internet environments and can be divided into volume, the total numbers of online WOM, and valence, which indicates the emotion.

\subsection{Volume and Valence of Online WOM}

Since the importance of online WOM has been emphasized, various studies have been published. First, experimental results about online WOM's volume are as follows: Liu (2006) has analyzed the relationship between the movie industry and online WOM and remarked that the volume of online WOM significantly affects the sales of movies. The volume of online WOM produced at such sites as movies.yahoo.com increases movie awareness among consumers, and, in turn, such awareness increases the sales of movies. In addition, Lin, $\mathrm{Wu}$, and Chen (2013) have examined the effects of volume and valence of online WOM on purchasing decisions and have concluded 
that the volume of online WOM positively affects purchasing intention. Also, it has been found that the volume of online WOM positively affects the sales of recorded music, as the volume increases the awareness of albums and thus increases the demand (Dewan and Ramprasad 2009). In addition, because the volume of online WOM reflects the number of consumers who purchase and use products, it causes an increase in product awareness and a decrease in uncertainty (Rosario et al. 2016). Last but not least, Seok, Lee, and Kim (2018) examined the mediation effect of volume of online WOM between corporate social responsibility news reports and firm value and found out that increase in corporate social responsibility news reports augments the volume of online WOM and thereby affects firm value.

The research on the valence of online WOM are as follows: First, research focusing on the movie industry indicated that the valence of online WOM does not significantly affect movie sales (Liu 2006). Since consumer movie preferences largely differ, the evaluations from others may not be of significant influence. On the other hand, there is research concluding that as positive online WOM increases, attitudes and purchasing intentions toward movies and the credibility of the online WOM are positively influenced (Doh and Hwang 2009). According to studies analyzing the relationship between online WOM and book sales, the effects on sales by negative evaluations of books are greater than by positive evaluations, and negative reviews negatively affect the sales (Chevalier and Mayzlin 2006). The trend of online WOM toward positivity or negativity significantly affects intention of delivery, degree of certain consumer intentions to deliver certain opinions to others when the consumer encounters online WOM, and the trend's influence is greater when it is negative (Baker, Donthu, and Kumar 2016). In addition, it has been known that when contents of online WOM are more positive, the sales of smart phones increase, and, as the online WOM of competing companies' products becomes more positive, the sales are negatively influenced (Gopinath, Thomas, and Krishnamurthi 2014). According to Luo (2009), who examined the effect of online WOM on stock price, when the degree of negativity in online WOM increases, its short-term and long-term influences on stock price become more negative. In addition, it has been found that groups of people exposed to positive product reviews have greater purchasing intentions than those who are exposed to the negative reviews ( $\mathrm{Yu}$, Ann, and Park 2011). Also, study about influence of online customer reviews on sales in hotel industry states that 1 percent increase in customer ratings results in about 2.6 percent increase in sales per room (Ogut and Tas 2012). Cui, Lui, and Guo (2012) examined the relationship between online reviews and sales of video games and concluded that both volume and valence of reviews had a positive effect on the sales. 
Regarding these preceding studies, we find that as online WOM becomes positive and as its volume increases, the online WOM tends to positively affect the brand's sales, and that the degree of the effect is different from that of negative online WOM. However, the reason that there are incompatible research results is because research subjects are limited to a few products or because the research focuses only on one communication channel (Rosario et al. 2016).

\subsection{Communication Channels for Online WOM}

This research chooses blog posts and Twitter among the numerous communication channels for online WOM and examines how the volume and valence from each channel affects the sales of automobiles. Most of the previous research chose only one online communication channel for the subject of their analysis, and there are only a few researches considering several channels (Seok, Lee, and Kim 2018). Because analyses with a single communication channel do not provide sufficient grounds for generalizing the effect of online WOM (Rosario et al. 2016), this research not only simultaneously considers two communication channels, Twitter and blog posts, but also aims to test the effects of volume and valence of each channel on the sales of automobile brands. The reasons we choose Twitter and blog posts, among the many various communication channels, and our hypotheses are as follows:

As information and communication technology develops, a number of communication channels for consumers to communicate online are increasing and their types are becoming diversified. Blogs are web-based information delivery media that enable users to express their opinions on a range of subjects, including opinions formed after purchasing or experiencing certain products, which allows them to share their opinions with readers and to communicate with many others. New blog posts are continuously created with new themes and messages, so blogging plays an important role in setting brand images and marketing strategies for companies in existing and new markets (Pal and Kapur 2010). Many blog posts are based on consumer experiences with certain products and enable quick communication with others, so it has been recognized that blogging has the power to attract many visitors (Wagner and Bolloju 2005). Blogs have also been used for many studies that analyze the effects of online WOM and have come to be seen as one of the most important communication channels for sharing opinions (Cox, Martinez, and Quinlan 2008).

Blogs are an important means of online WOM in the sense that it turns potential consumers exposed to blog posts into customers and provides opportunities for inducing recommendations to other consumers (Kim 2010; Pan, Maclaurin, and Crotts 2007), and, therefore, it is one of 
the most valuable communication channels for connecting products and consumers. Blogs deliver information on product users' detailed experiences with the products through not only text but also pictures and videos. In the process of making purchasing decisions, consumers tend to rely on the thoughts of other consumers to reduce uncertainty about products and therefore are influenced by the valence of the online WOM (Banerjee 1992). Since blogging has no limit on the number of words written for a post, it is useful for consumers to share their experiences. It has been found that about $75 \%$ of consumers who gather information on certain products from blog posts consider the context of the posts to be important, and the proportion is greater than that of consumers who gather information from electronic newspapers or journals (Johnson and Kaye 2004). Therefore, for consumers who seek information before purchasing certain products, a blog's valence, the positive or negative emotion associated with a product, may influence more significantly than its volume. Based on such an expectation, the first hypothesis is as follows:

Hypothesis 1: In the case of blogs, as the degree of positivity of online WOM increases, the sales increase.

Microblogging is defined as a modern phenomenon whereby one communicates with others through short written messages through a web-service (Kaplan and Haenlein 2011), the most representative microblogging service being Twitter. Twitter is a representative communication channel. It has 230 million users as of November 2013, and about 400 million messages are uploaded every day (Shah, Ahmad and Ahmad 2013). In addition, because increases in the supply rate of smart phones and the growth of Twitter are closely related, it has high potential (Hennig-Thurau, Wiertz, and Feldhaus 2015). Known as the largest and most broadly known microblogging website, Twitter is a social media service appropriate for researching the effect of online WOM (Jansen et al. 2009). There are numerous studies that choose Twitter as the online communication channel of their focus (Jansen et al. 2009; Jin and Phua 2014; HennigThurau, Wiertz, and Feldhaus 2015; Sotiriadis and Zyl 2013). Jansen et al. (2009) insist that Twitter can help viral marketing, branding, and customer management, and that Twitter is a useful marketing tool because most Twitter users leave questions about certain brands and answers on Twitter. Furthermore, Rui, Liu, and Whinston (2010) point out that there are large amounts of information on Twitter, doubling as valuable data for companies and researchers.

Since the volume of Twitter represents how many consumers have used certain products, it will increase product awareness and decrease uncertainties regarding the product for latent consumers. (Chintagunta, Gopinath, and 
Venkataraman 2010; Park, Gu, and Lee 2012). Jansen et al. (2009) claim that most Twitter users tend to focus on sharing information, such as answering questions about products, rather than on sharing emotions on certain products. In addition, since Twitter limits the number of words written for each post, users cannot fully express their thoughts and feelings (Jansen et al. 2009). Therefore, because Twitter is not so much suited for expressing emotions and because the volume of online WOM has been known to increase purchasing intentions (Lin, Wu, and Chen 2013), consumers may be influenced more by volume rather than valence. Considering such a line of reasoning, we draw another hypothesis as follows:

Hypothesis 2: As the volume of Twitter increases, the sales increase.

\section{Research Design}

\subsection{Measurement of Variable and Sample Selection}

In order to test our hypotheses, we have decided to gather data from the Korean automobile industry. There are two underlying reasons for such a selection. First, numerous automobile brands are under severe internal competition (Seok, Lee, and Kim 2018). We expect online WOM marketing strategies as an important method for achieving competitive advantage, and such characteristics of the automobile market can help reveal the effect of online WOM. Second, the Korea Automobile Manufacturers Associations (KAMA) and Korea Automobile Importers and Distributors Association (KAIDA) publicize the monthly sales of each brand with sufficient details, revealing the characteristics of each brand's automobiles. In other words, we can build reliable longitudinal data.

We collected data from four different sources. The first source is a website called Danawa (auto.danawa.com). It collects data from KAMA and KAIDA to show each brand's sales information; so, we could gather each brand's monthly sales data through this website and use this data as our dependent variable. The second source is Socialmetrics, a big data solution platform managed by Daumsoft, one of the main search engines in Korea. When a certain keyword is entered in a Socialmetrics search, not only the amount of online WOM in social media is provided but also the number of positive, negative, or neutral words. Therefore, this source enabled us to derive information on online WOM volume and valence in social media. The valence variable in this research is defined as the ratio of positive words to total words. The third source is Naver (autonaver.com), which is the biggest search engine in Korea. It offers detailed information on 115 automobile 
brands, including such information as price, displacement, fuel efficiency, automobile size, and so on (Seok, Lee, and Kim 2018). Through this source, we compiled the characteristics of certain automobiles. Lastly, in order to consider macroeconomic factors, we collected the GDP, unemployment rate, and monthly average interest rate for household loans from Statistics Korea. Since the goal of the research is to clarify how online WOM volume and valence of certain brands affect the monthly sales, we have attempted to control any other variables that could influence the sales. Because each brand sells several different models, we have had to generate a representative value of price, capacity, and fuel efficiency for each brand. To do so, we first collected data on price, capacity, and fuel efficiency for the top 3 monthly best-selling models (Peng et al. 2014). We have confirmed that sales of the top three best-selling models of each brand account for 80 percent of total sales, so if the representative values are calculated from characteristics of the top three models, most of the brand-wise characteristics can be satisfactorily controlled (Seok, Lee, and Kim 2018). Therefore, we have calculated monthly weighted averages for each of the control variables and assumed these weighted averages as the representative values.

For example, the representative price of a Renault Samsung in January 2014 is calculated as follows: The top three best-selling models for the month were the SM5, SM3, and QM5.
The sales amounts were 1884, 1427, and 603 respectively, and the prices at maximum trim were KRW 2,900, KRW 1,978, and KRW 3,310 ten thousand respectively. Calculating using Equation (1), we defined the representative price of Renault Samsung to be KRW 2627.02 ten thousand.

$$
\begin{gathered}
\left(2900 \times \frac{1884}{(1884+1427+603)}\right)+\left(1978 \times \frac{1427}{(1884+1427+603)}\right) \\
+\left(3310 \times \frac{603}{(1884+1427+603)}\right)=2627.02
\end{gathered}
$$

To check the effect of online WOM, we collected data on each of the top twenty brands in December 2017 from auto.danawa.com. Then we selected nineteen brands that sold at least a hundred cars every month for four years, a period between January 2014 and December 2017. Thus, our data consists of 19 brands and 912 observations. The details can be found in Table 1.

\subsection{Research Model}

To examine the effects of online WOM from Twitter and blog posts, we establish three models. First, model (1)'s dependent variable is the natural log of monthly sales ( $\ln ($ Sales $)$ ), and the independent variables are the natural log of blog volume (ln(BLOG VOLUME)) and blog valence ( $\ln ($ BLOG VALENCE)). Control variables are brand-wise price (PRICE), fuel 
$\langle$ Table 1〉 measurement and source of each variables

\begin{tabular}{|c|c|c|}
\hline Variable & Description & Source \\
\hline $\begin{array}{l}\text { Natural log of sales } \\
(\ln (\text { SALES }))\end{array}$ & Natural log of sales of each brand at time $t$ & auto.danawa.com \\
\hline $\begin{array}{l}\text { Natural log of volume of blog } \\
(\ln (\text { BLOG VOLUME }))\end{array}$ & Volume of blog posts for each brand at time $t$ & \multirow{4}{*}{ socialmetrics } \\
\hline $\begin{array}{l}\text { Valence of blog } \\
\text { (BLOG VALENCE) }\end{array}$ & Valence of blog posts for each brand at time $t$ & \\
\hline $\begin{array}{l}\text { Natural log of volume of Twitter } \\
(\ln (\text { TWITTER VOLUME }))\end{array}$ & Volume of Twitter posts for each brand at time $t$ & \\
\hline $\begin{array}{l}\text { Valence of Twitter } \\
\text { (TWITTER VALENCE) }\end{array}$ & Valence of Twitter posts for each brand at time $t$ & \\
\hline $\begin{array}{l}\text { Price } \\
(\mathrm{PRICE})\end{array}$ & $\begin{array}{l}\text { Weighted average of price for each brand at time } \\
t \text { (unit: KRW thousand) }\end{array}$ & \multirow{4}{*}{ auto.naver.com } \\
\hline $\begin{array}{l}\text { Fuel efficiency } \\
\text { (FUEL) }\end{array}$ & $\begin{array}{l}\text { Weighted average of fuel efficiency for each } \\
\text { brand at time } t \text { (unit: } \mathrm{km} / \mathrm{l} \text { ) }\end{array}$ & \\
\hline $\begin{array}{l}\text { Displacement } \\
\text { (CC) }\end{array}$ & $\begin{array}{l}\text { Weighted average of displacement for each brand } \\
\text { at time } t \text { (unit: } 1000 \mathrm{cc} \text { ) }\end{array}$ & \\
\hline $\begin{array}{l}\text { Size of automobile } \\
\text { (SIZE) }\end{array}$ & $\begin{array}{l}\text { Weighted average of size of automobile for each } \\
\text { brand at time } t \\
\text { (1: light, } 2 \text { : subcompact, } 3 \text { : compact, } 4 \text { : mid-size, } \\
\text { 5:full-size) }\end{array}$ & \\
\hline $\begin{array}{l}\text { Average interest rate for } \\
\text { household loan(LOAN RATE) }\end{array}$ & Monthly average interest rate for household loan & \multirow{3}{*}{ Statistics Korea } \\
\hline GDP (GDP) & Quarterly GDP (unit: KRW 1 trillion) & \\
\hline $\begin{array}{l}\text { Unemployment rate } \\
\text { (UNEMPLOY) }\end{array}$ & Monthly unemployment rate (unit: \%) & \\
\hline $\begin{array}{l}\text { National brand / Foreign brand } \\
\text { (FOR) }\end{array}$ & $\begin{array}{l}\text { National brand: } 0 \\
\text { Foreign brand: } 1\end{array}$ & \\
\hline Year dummy(YD) & $2014: 0,2015: 1,2016: 2,2017: 3$ & \\
\hline Quarter dummy (QD) & $\begin{array}{l}1^{\text {st }} \text { quarter: } 0,2^{\text {nd }} \text { quarter: } 1,3^{\text {rd }} \text { quarter }: 2,4^{\text {th }} \\
\text { quarter: } 3\end{array}$ & \\
\hline
\end{tabular}

efficiency (FUEL), displacement (CC), size of automobile (SIZE), monthly average interest rate for household loan (LOAN RATE), unemployment rate (UNEMPLOY), GDP (GDP), foreign brand dummy (FOR), year dummy (YD) and quarter dummy (QD).
When establishing this model, we manipulated the time period to reveal causal relationships more precisely: time $\mathrm{t}-1$ was used for blog's and Twitter's online WOM, and time $t$ was used for monthly sales. Much research so far has manipulated time period to clarify causal 
relationships (Seok et al. 2017; Servaes and Tamayo 2013).

$$
\begin{aligned}
& \ln \left(\text { SALES }_{i t}\right)=\beta_{0}+\beta_{1} \ln \left(\text { BLOG VOLUME }_{i t-1}\right) \\
& +\beta_{2} \text { BLOG VALENCE }_{i t-1}+\beta_{3} \text { PRICE }_{i t} \\
& +\beta_{4} \text { PRICE }_{i t}^{2}+\beta_{5} \text { FUEL }_{i t}+\beta_{6} C C_{i t} \\
& +\beta_{7} \text { SIZE }_{i t}+\beta_{8} \text { UNEMPLOY }_{t}+\beta_{9} G D P_{t} \\
& +\beta_{10} \text { FOR }_{i}+\beta_{11} \text { LOAN RATE }_{t}+\sum_{t^{\prime}=1}^{3} \gamma_{t^{\prime}} Y D_{t^{\prime}} \\
& +\sum_{t^{\prime \prime}=1}^{3} \gamma_{t^{\prime \prime}} Q D_{t^{\prime \prime}}, \quad i=1, \cdots, 19 t=1, \cdots, 48
\end{aligned}
$$

model (1)

Model (2)'s dependent variable is the natural $\log$ of monthly sales $(\ln ($ Sales $))$, and the independent variables are the natural log of Twitter volume (ln(TWITTER VOLUME)) and Twitter valence (ln(TWITTER VALENCE)). Control variables are the same as those of Model (1).

$$
\begin{aligned}
& \ln \left(\text { SALES }_{i t}\right)=\beta_{0}+\beta_{1} \ln \left(\text { TWITTER VOLUME }_{i t-1}\right) \\
& +\beta_{2} \text { TWITTER VALENCE }_{i t-1}+\beta_{3} \text { PRICE }_{i t} \\
& +\beta_{4} \text { PRICE }^{2}{ }_{i t}+\beta_{5} \text { FUEL }_{i t}+\beta_{6} \text { CC }_{i t}+\beta_{7} \text { SIZE }_{i t} \\
& +\beta_{8} \text { UNEMPLOY }_{t}+\beta_{9} G D P_{t}+\beta_{10} \text { FOR }_{i} \\
& +\beta_{11} \text { LOAN RATE }_{t}+\sum_{t^{\prime}=1}^{3} \gamma_{t^{\prime}} \text { YD }_{t^{\prime}} \\
& +\sum_{t^{\prime \prime}=1}^{3} \gamma_{t^{\prime \prime}} Q_{t^{\prime \prime}}, \quad i=1, \cdots, 19 \quad t=1, \cdots, 48
\end{aligned}
$$

Model (3)'s dependent variable is the natural log of monthly sales ( $\ln (\mathrm{SALES})$ ), and independent variables are the natural log of blog volume (ln (BLOG VOLUME) ), blog valence (ln(BLOG VALENCE)), natural log of Twitter volume (ln(TWITTER VOLUME)), and Twitter valence (ln(TWITTER VALENCE)). Control variables are the same as those of Model (1).

$$
\begin{aligned}
& \ln \left(\text { SALES }_{i t}\right)=\beta_{0}+\beta_{1} \ln \left(\text { BLOG VOLUME }_{i t-1}\right) \\
& +\beta_{2} \text { BLOG VALENCE }_{i t-1}+\beta_{3} \ln \left(\text { TWITTER VOLUME }_{i t-1}\right) \\
& +\beta_{4} \text { TWITTER VALENCE }_{i t-1}+\beta_{5} \text { PRICE }_{i t}+\beta_{6} \text { PRICE }^{2}{ }_{i t} \\
& +\beta_{7} \text { FUEL }_{i t}+\beta_{8} C_{i t}+\beta_{9} \text { SIZE }_{i t}+\beta_{10} \text { UNEMPLOY }_{t} \\
& +\beta_{11} \text { GDP }_{t}+\beta_{12} \text { FOR }_{i}+\beta_{13} \text { LOAN RATE }_{t}+\sum_{t^{\prime}=1}^{3} \gamma_{t^{\prime}} Y_{t^{\prime}} \\
& +\sum_{t^{\prime \prime}=1}^{3} \gamma_{t^{\prime \prime}} \text { QD }_{t^{\prime \prime}}, \quad i=1, \cdots, 19 \quad t=1, \cdots, 48
\end{aligned}
$$

model (3)

Since the data for this research are longitudinal or panel type, consisting of 19 brands and 48 months, the appropriate analysis method is a panel regression model. Standard panel regression model can be expressed as follows:

$$
y_{i t}=x^{\prime}{ }_{i t} \beta+\alpha_{i}+u_{i t} \quad i=1, \cdots, \mathrm{N} \quad, \mathrm{t}=1, \cdots, \mathrm{T}
$$

In equation (2), variable $\alpha_{i}$ is not varied as the time changes yet varied as the panel changes, and variable $u_{i t}$ is varied as both the time and panel change. Generally, choice of 
analysis method depends on how to infer the $\alpha_{i}$ (Min and Choi 2016; Seok, Kim, and Go 2019; Wooldridge 2016). Typically, there are three analysis methods: first is the fixed effect model, which assumes $\alpha_{i}$ is a parameter to be estimated; second is the random effect model, which assumes $\alpha_{i}$ as a random variable; third is the Pooled OLS method, which does not consider the characteristics of panel data (Min and Choi 2016). In equation (2), if error term $\alpha_{i}$ is zero for all i, we could apply the Pooled OLS method. If $\alpha_{i}$ is a constant number, which is not varied as the time changes yet varied as the panel changes, we could apply the fixed effect model. If $\alpha_{i}$ is a random variable, we could apply the random effect model (Seok, Kim, and Go 2019; Wooldridge 2016).

The reasons we chose the random effect model to test hypotheses are as follows: First, we applied the Hausman test to figure out whether the random effect model would be more appropriate to use than the fixed effect model. According to econometrics theories, if covariances of $x_{i t}$ and $\alpha_{i}$ are zero $\operatorname{COV}\left(x_{i t}\right.$, $\left.\alpha_{i}\right)=0$ ), then the estimator of both models would be consistent, though it has been found that the random effect model is more efficient. On the other hand, if the covariance of $x_{i t}$ and $\alpha_{i}$ is not zero $\left(\operatorname{COV}\left(x_{i t}, \alpha_{i}\right) \neq 0\right)$, then we have to use the fixed effect model, because the estimator derived from the random effect model cannot become a consistent estimator that causes an outbreak of systematic difference in the estimated result. Since we could not reject the null hypothesis of the Hausman test 'COV $\left(x_{i t}, \alpha_{i}\right)=0$ ' at $5 \%$ significance level $\left(x_{(18)}^{2}: 18.14, p>0.05\right)$, we applied the random effect model to achieve a more efficient estimator (Hausman 1978).

Next, we applied Breusch and Pagan's LM test (Lagrange Multiplier Test) to check whether the random effect model would be more appropriate for the analysis than the Pooled OLS method. If error term $\alpha_{i}$ is assumed to have a random effect, one could test for significance in the random effect model, and, in such a case, the null hypothesis would be as follows (Breusch and Pagan 1980):

$$
H_{0}=\operatorname{var}\left(\alpha_{i}\right)=\sigma_{\alpha}^{2}=0
$$

If the null hypothesis is rejected, one has to apply the random effect model to consider the characteristics of a panel group. According to a result of the LM test, the null hypothesis $\left(\sigma_{\alpha}^{2}=0\right)$ is rejected at the $5 \%$ significance level $\left(x_{(1)}^{2}: 9897.37, p<0.001\right)$, leading us to decide that applying the random effect model is indeed appropriate. 


\section{Analysis Result}

\subsection{Descriptive Statistics}

Descriptive statistics of the variables are provided in Table 2. The average monthly sales amount, the dependent variable, is about 7,364 automobiles. The monthly average volume of blog posts, the independent variable, is about 6,389 , and that of the valence of blog posts is $58 \%$. Also, the monthly average volume of Twitter posts, another independent variable, is about 5,069, and that of the valence of Twitter posts is $44 \%$. The monthly average sales price of automobiles is about KRW 60 million, and the average fuel efficiency and displacement are $12.62 \mathrm{~km} / 1$ and $2860 \mathrm{cc}$, respectively. The average automobile size is 3.5 , which indicates that the favored automobile size is between compact and midsized. The average monthly interest rate for household loans is $3.42 \%$, and the average monthly unemployment rate is $3.61 \%$. Lastly, the average quarterly GDP is KRW 401 trillion. Among observations, the number of automobiles made by Korean brands is 240 , and those made by foreign brands is 672 .

Table 3 presents the result of correlation coefficients. The significant correlations, whose amounts are greater than 0.6, are indicated at several pairs of variables: sales and volume of blog post; fuel efficiency and sales; displacement and price; displacement and fuel efficiency; size of automobile and displacement. Since the high correlations may yield a multi-collinearity problem, we have estimated model (3) with a

$\langle$ Table 2〉 descriptive statistics of main variables

\begin{tabular}{lcccc}
\hline \multicolumn{1}{c}{ Variable } & Mean & S.D. & Min & Max \\
\hline In(SALES) & 7.17 & 1.87 & 2.48 & 11.31 \\
In(BLOG VOLUME) & 8.30 & 0.88 & 6.28 & 11.33 \\
BLOG VALENCE & 0.58 & 0.09 & 0.17 & 0.93 \\
In(TWITTER VOLUME) & 7.72 & 1.33 & 4.51 & 11.05 \\
TWITTER VALENCE & 0.44 & 0.18 & 0.02 & 0.99 \\
PRICE & 6.04 & 3.86 & 1.71 & 22.16 \\
FUEL & 12.62 & 2.55 & 6.88 & 18.31 \\
CC & 2.86 & 0.80 & 1.33 & 5.97 \\
SIZE & 3.52 & 0.62 & 0.000 & 4.90 \\
LOAN RATE & 3.42 & 0.32 & 2.95 & 4.15 \\
UNEMPLOY & 3.61 & 0.45 & 3 & 4.9 \\
GDP & 401.40 & 23.09 & 368.88 & 441.25 \\
\hline & & \multicolumn{4}{c}{ Frequency } \\
\hline \multirow{2}{*}{ FOR } & & \multicolumn{3}{c}{ national brand: 240} \\
\end{tabular}


$\langle$ Table 3〉 correlation coefficients

\begin{tabular}{lcccccccccccc}
\hline & 1 & 2 & 3 & 4 & 5 & 6 & 7 & 8 & 9 & 10 & 11 & 12 \\
\hline 1. $\ln$ (SALES) & 1 & & & & & & & & & & & \\
2. $\ln$ (BLOG VOLUME) & .569 & 1 & & & & & & & & & \\
3. BLOG VALENCE & .667 & .264 & 1 & & & & & & & & \\
4. $\ln$ (TWITTER VOLUME) & .396 & .521 & .064 & 1 & & & & & & & \\
5. TWITTER VALENCE & -.064 & -.014 & .137 & -.069 & 1 & & & & & & \\
6. PRICE & -.415 & -.118 & .017 & .005 & .024 & 1 & & & & & \\
7. FUEL & .574 & .361 & .024 & .124 & .040 & -.504 & 1 & & & & \\
8. CC & -.453 & -.147 & -.033 & .110 & -.006 & .755 & -.570 & 1 & & & \\
9. SIZE & -.340 & -.139 & -.028 & .056 & -.024 & .456 & -.344 & .592 & 1 & & \\
10. LOAN RATE & -.065 & -.088 & .040 & -.006 & .042 & .041 & -.015 & .060 & .059 & 1 & & \\
11. UNEMPLOY & -.018 & -.120 & -.168 & -.028 & .028 & -.002 & -.025 & -.016 & -.019 & .012 & 1 & \\
12. GDP & .085 & .405 & .275 & .064 & -.006 & -.040 & -.077 & -.083 & -.052 & -.460 & .026 & 1 \\
\hline
\end{tabular}

Pooled OLS method and then computed the Variation Index Factor, VIF, for each variable. The average VIF is 1.85 , and the displacement variable has the greatest VIF at 3.58. Yet, such a value is not meaningful enough to cause any worry about the multi-collinearity problem, so we conclude that the correlations may not distort the estimation results. We plan to estimate the models with our data set that consists of 19 brands and 912 observations, yet because we have manipulated the time period while structuring the models, we ended up using 893 observations.

\subsection{Hypothesis Testing}

Table 4 indicates the results from panel regression analyses of the three different models. Model (1) is set to test the first hypothesis: the valence of blog post will affect sales. The results of the analysis indicate that the volume of blog posts does not significantly affect sales $(\beta=.045 ; p>05)$ and that the valence of blog posts significantly affect sales $(\beta=.330$; $\mathrm{p}\langle 0.05)$. With this result, the first hypothesis is supported, and we conclude that the valence of blog posts uploaded at time $\mathrm{t}-1$ positively influences sales at time $t$.

Model (2) is then evaluated to decide whether the volume of Twitter posts affect sales positively. The results of this analysis indicate that the volume of Twitter posts significantly affect sales ( $\beta=.044 ; p<0.05)$ and that the valence of Twitter posts also significantly affect sales $(\beta=.135 ; p<0.05)$. With this result, the second hypothesis is also supported, and we conclude that both the valence and the volume of Twitter posts written at time t-1 positively 
$\langle$ Table 4〉 panel regression analysis

\begin{tabular}{|c|c|c|c|}
\hline VARIABLES & MODEL 1 & MODEL 2 & MODEL 3 \\
\hline $\ln ($ BLOG VOLUME) & .045 & & .042 \\
\hline BLOG VALENCE & $.330^{*}$ & & $.288^{*}$ \\
\hline ln(TWITTER VOLUME) & & $.044^{*}$ & $.041 *$ \\
\hline TWITTER VALENCE & & $.135^{*}$ & .123 \\
\hline FOR & $-3.225^{* * *}$ & $-3.232^{* * *}$ & $-3.210 * * *$ \\
\hline PRICE & -.072 & $-.079 *$ & $-.076^{*}$ \\
\hline PRICE^2 & .002 & .002 & .002 \\
\hline FUEL & $.051^{* * *}$ & $.048^{* * *}$ & $.049^{* * *}$ \\
\hline $\mathrm{CC}$ & -.033 & -.033 & -.029 \\
\hline GDP & .005 & .002 & .005 \\
\hline UNEMPLOY & -.065 & -.069 & -.068 \\
\hline SIZE & $.195^{* * *}$ & $.186^{* * *}$ & $.192^{* * *}$ \\
\hline LOAN RATE & -.131 & -.078 & -.132 \\
\hline CONSTANT & $6.630 * * *$ & $7.781^{* * *}$ & $6.409 * *$ \\
\hline Observations & 893 & 893 & 893 \\
\hline Number of Brand & 19 & 19 & 19 \\
\hline Year dummy & YES & YES & YES \\
\hline Quarter dummy & YES & YES & YES \\
\hline Adjusted R Squared & .244 & .245 & .249 \\
\hline
\end{tabular}

affect the sales at time $t$.

Lastly, model (3) is estimated to achieve a more precise result. Unlike the other two, this model includes all four independent variables to mutually control the online WOM from Twitter and from blog posts. The results of this analysis suggest that the volume of blog posts do not significantly affect sales $(\beta=$ $.042 ; \mathrm{p}>0.05)$ while the valence of blog posts positively influences sales $(\beta=.288 ; \mathrm{p}<0.05$ ), and that the volume of Twitter posts significantly affect sales $(\beta=.041 ; \mathrm{p}<0.05)$ while the valence of Twitter posts do not significantly affect sales $(\beta=.123 ; \mathrm{p}>0.05)$. Hence, the more positive a blog post is, and the more Twitter post quantity increases, the more positively affected sales of automobiles will be in the succeeding month. By this analysis, we conclude that the valence of blog posts and the volume of Twitter posts positively affect sales, and our hypotheses are supported.

The analyses of these three models indicate that foreign brand dummy negatively affects sales, and such an indication may reflect the reality that the national brand automobiles are purchased more than the foreign brand in the 
national market. Fuel efficiency is estimated to affect sales positively. Because high fuel efficiency is currently favored by many consumers, such a preference may lead to an increase in sales. The size of automobiles positively and significantly affects sales, revealing that sales increase as the size of the automobile increases. Lastly, we find that price has a negative impact on sales in both model (2) and (3). In other words, if the price increases, the sales will decrease.

\subsection{Discussion}

This research is intended to clarify the effect of online WOM from two different communication channels, blogs and Twitter, on automobile sales. Because these communication channels have their own unique characteristics, we judged that their words of mouth would also have different degrees of effect. In order to analyze how the online WOM affects the sales of automobile companies and how the effects of these communication channels differ, this research introduced three different models to test our hypotheses. First, the results from the estimation of model (1) indicate that the valence of blog posts at time $t-1$ significantly affect sales, meaning that a greater proportion of positivity in blog posts positively affects the sales. In the process of making purchasing decisions, consumers tend to rely on other consumer opinions to reduce uncertainty about products and therefore are influenced by valence of online WOM (Banerjee 1992). Because blog posts do not limit the number of words, a blog is a proper communication channel to share user experiences with enough details and, in turn, offers a large amount of both positive and negative information to consumers who seek product information before purchase. Therefore, since consumers explore numerous blog posts to gather sufficient information before purchasing automobiles, we conclude that the proportion of positivity in a blog post significantly affects purchasing decisions.

A result of model (2), which aims to understand the relationship between Twitter and automobile sales, indicates that both the valence and the volume of Twitter posts written at time $t-1$ positively affect sales at time $t$. This result reflects that as the volume and valence of Twitter increase, sales also increase. However, results from the estimation of model (2) do not coincide with that of model (3). Model (3) accounts for online WOM information from both communication channels, enabling us to more clearly examine the effect of one channel with the effect of the other channel being controlled. The results from model (3) indicate that like the results of model (1), only the valence of blog posts affect sales and that unlike the results of model (2), only the volume of Twitter posts provides a significant influence on sales, as sales increase as the number of Twitter posts increase. We compare the adjusted 
R squared of model (2) and model (3): .245 and 249 , respectively, and the comparison indicates that model (3) explains our data better. Therefore, in the case of online WOM from Twitter, we conclude that only the volume affects sales significantly. Most Twitter users focus on sharing product information, rather than evaluating products (Jansen et al. 2009). Since the volume of Twitter posts represents how many consumers have used certain products, it will increase product awareness and decrease the uncertainty regarding a product for latent consumers (Chintagunta, Gopinath, and Venkataraman 2010; Park, Gu, and Lee 2012). According to Chi, Yeh, and Yang (2009), brand awareness positively affects purchase intention. In other words, the share of product information is more prevalent than the share of emotion in Twitter, and as the volume of online WOM increase, brand awareness increase, that increase eventually resulting in higher purchase intentions. Since sharing detailed descriptions on product experience is restricted by the limitation on the number of words one can write in a post, our hypothesis that the volume of Twitter posts would positively affect the sales is supported. Furthermore, this result shares a similar view with the research of Chung and Kim (2011), which claims that the amount of online WOM generated from web communities and social networks positively affects the sales of cell phones.

Lastly, we examined the causal relationships between the valence of blog posts and the sales of automobiles and between the volume of Twitter posts and the sales of automobiles. This research intentionally manipulated the time period to highlight the temporal causal relationship, using data of independent variables at time $\mathrm{t}-1$ to evaluate the sales at time $\mathrm{t}$. However, there is some research that has proven the reverse causal relationship between online WOM and sales (Duan, Gu, and Whinston 2008; Lee, Cha, and Kim 2016). Therefore, we performed an additional analysis to make clear the order of the causal relationship. Knowing of numerous preceding studies that use the Granger causality test to elucidate causal relationships (Aydin and Malcioglu 2016; Dewan and Ramprasad 2009; Luo 2009; Yüksel 2017), we performed the Dumitrescu-Hurlin Granger causality test to assess the relationship between online WOM and sales. Granger (1969) proposed a method to clarify the order of causality between two different time-series variables. $x_{t}$ and $y_{t}$ are the time-series variables, and the equation (3) helps us to examine whether $\mathrm{x}$ precedes with $\mathrm{y}$.

$$
y_{t}=\alpha+\sum_{k=1}^{K} \beta_{k} y_{t-k}+\sum_{k=1}^{K} \gamma_{k} x_{t-k}+\varepsilon_{t}
$$
equation (3)

If the value of $\mathrm{x}$ and the value of $\mathrm{y}$ in the past work as important predictor variables in estimating $\mathrm{y}$, we can determine that $\mathrm{x}$ granger 
causes y. The null hypothesis for the Granger causality test is expressed in equation (4). If we cannot reject the null hypothesis, the value of $\gamma$ is equal to zero, meaning that $\mathrm{x}$ cannot be a significant predictor variable for estimating $y$.

$$
H_{0}: \gamma_{1}=\cdots=\gamma_{K}=0 \cdots \text { equation }(4)
$$

On the other hand, if the null hypothesis is rejected, then one can conclude that $\mathrm{x}$ is preceded by y (Lopez and Weber 2018). Dumitrescu and Hurlin (2012) proposed the Dumitrescu-Hurlin Granger causality test, which is developed from the original Granger test. Though similar to equation (3), it has a slightly different form, expressed in equation (5), to consider individual characteristics. Including individual $i$ at time $t$ in the equation allows us to estimate the coefficient for individual $i$. Considering the characteristics of individuals, rather than those of a group, the test lets us clearly identify the order of the causal relationship.

$$
y_{i, t}=\alpha_{i}+\sum_{k=1}^{K} \beta_{i k} y_{i, t-k}+\sum_{k=1}^{K} \gamma_{i k} x_{i, t-k}+\epsilon_{i, t}
$$$$
\text { equation (5) }
$$

The null hypothesis for the Dumitrescu-Hurlin Granger causality test is expressed as follows:

$$
H_{0}: \gamma_{i 1}=\cdots=\gamma_{i K}=0 \quad \forall i=1, \cdots, \mathrm{N}
$$

equation (6)
For the Dumitrescu-Hurlin Granger causality test, we need to calculate Wald statistics to generate test statistics for individual. As written in equation (7) and (8), we use the average of all individual Wald statistics to find the standardized statistics $\bar{Z}$, and this $\bar{Z}$ is used for the hypothesis testing.

$$
\begin{aligned}
& \bar{W}=\frac{1}{N} \sum_{i=1}^{N} W_{i} \\
& \bar{Z}=\sqrt{\frac{N}{2 K}} \cdot(\bar{W}-K) \frac{d}{T, N \rightarrow \infty} N(0,1)
\end{aligned}
$$

In order to proceed with the Granger causality test, we estimated several criterion values such as AIC (Akaike's Information Criterion), BIC (Bayesian Information Criterion), and HQIC (Hannan-Quinn Information Criterion) to find an optimal lag, and then we estimated the model with this optimal lag (Lopez and Weber 2018).

Table 5 shows the results of the DumitrescuHurlin Granger causality test. The presented results indicate that the valence of blog posts and the volume of Twitter posts are meaningful predictor variables for predicting the sales of automobiles in the next period and that they predict sales. That is, the valence of blog posts and the volume of Twitter posts are predictive of sales and their effects on sales increases are significant. 
〈Table 5〉 result of Dumitrescu-Hurlin granger causality test

\begin{tabular}{cc}
\hline Null Hypothesis & $\bar{Z}$ \\
\hline BLOG VALENCE & $2.155^{*}$ \\
does not granger cause & \\
$\ln$ (SALES) & \\
& \\
$\ln$ (TWITTER VOLUME) & $4.578^{* * *}$ \\
does not granger cause & \\
$\ln ($ SALES) & \\
\hline$*: p<0.05, * *: p<0.01,{ }^{* * *}: p<0.001$ &
\end{tabular}

\section{Conclusion}

\subsection{Research Summary}

As the development of information and communication technologies results in increasing social network users, the influence of online WOM continuously increases more than that of traditional media. Therefore, to modern companies, the key issue is the management and application of online WOM in social media (Moorman 2014). So far, numerous researches into online WOM has been published, but most research has focused on temporary experience goods, such as books and movies, and on a single online communication channel (Liu 2006). Such circumstances are due to the limitations on gathering online WOM data, causing difficulty in generalizing the effects of online WOM. This research aims to understand the relationship between online WOM and automobiles, which are durable goods. To do so, we choose 19 brands whose average monthly sales amount to more than 100 during a period between January 2014 and December 2017 as a sample, and we gathered 912 observations to create time-series data for those brands over the course of 48 months. We selected Twitter and blogs as two different communication channels for comparison, and the reasons are as follow: First, Twitter is a representative communication channel with 230 million users as of November 2013, and about 400 million messages are uploaded every day (Shah, Ahmad and Ahmad 2013). Because the supply rate of smart phones is closely related to the growth rate of Twitter users, Twitter indeed takes center-stage (HenningThurau, Wiertz and Feldhaus 2015) and is the most frequently used microblogging site for preceding research. We thus concluded that Twitter is a proper communication channel to analyze online WOM (Jansen et al. 2009). Second, blogs are a web-based information delivery media that enables users to describe their experiences and feelings about certain products and to receive the opinions of others, allowing for communication with many others. New blogs are continuously created with new themes and messages, so blogging plays an important role in setting brand images and marketing strategies for companies in existing and new markets (Pal and Kapur 2010). In addition, blogs have also been used for many studies that analyze the effects of online 
WOM, and it has been found that blogs are one of the most important communication channels for sharing opinions (Cox, Martinez, and Quinlan 2008). For these reasons, this research used Twitter and blogs as our two different online communication channels for this study.

Through empirical analysis, we discovered several findings. First, the valence of blog posts significantly and positively affects the sales of automobiles. Blogs allow users to deliver their messages with pictures and videos, and many blog posts share consumer experiences on certain products and enable quick communication with others. It is understood that blogs have a power to attract many visitors (Wagner and Bolloju 2005). Furthermore, since blog users tend to post very detailed experiences and emotions after actually using the product, valence may serve as a more important factor than volume. Second, the volume of Twitter posts affects sales positively. Because of limits on the number of words and the means of delivering messages, Twitter posts cannot share experiences in as detailed of a way as that of blogs can. Therefore, consumers may be influenced more by the number of exposures of the brand in which they are interested than by the content of posts. In other words, brand or product awareness increases as the volume increases, and, in turn, such increases result in a positive influence on sales. Such results are similar to other research findings in that the volume of online WOM positively affects business performance (Chung and Kim 2011; Doh and Hwang 2009; Liu 2006). Lastly, we attempted to clarify the causal relationships between the valence of blog posts and sales and between the volume of Twitter posts and sales. Although the model structures are built in accordance with hypotheses by manipulating the time period, some of the research that examines the effects of online WOM has proven that online WOM is influenced by dependent variables (Duan, Gu, and Whinston 2008; Lee, Cha, and Kim 2016). Therefore, we statistically approached our models through the Dumitrescu-Hurlin Granger causality test, which clearly showed a causal relationship, to check whether our independent variables do precede the dependent variables. The results of the test indicate that the valence of blog posts and the volume of Twitter posts are significant predictor variables for estimating sales for the next financial period and prove that our independent variables take place before the sales. In other words, we conclude that the valence of blog posts and the volume of Twitter posts are preceded and significantly and positively affect sales.

\subsection{Academic and Practical Implications}

The academic implications of this research are as follows: First, we empirically examined the effect of representative online WOM on 
automobile sales. Our models consist of both micro factors, such as price and displacement and macro factors, including unemployment rate and GDP. In addition, the models were formulated using proper methods and criteria based on econometrics theories. Second, most of the previous research on online WOM used data on temporary experience goods, such as books and movies (Chevalier and Mayzlin 2006: Liu 2006; Qin 2011), but this research focuses on the role of online WOM in a durable goods market. Specifically, this research examines the automobile industry, the prices of which are relatively higher than other durable goods, as the subject of analysis. In other words, this research reveals that online WOM still plays an important role in the sales of expensive products. Third, our model includes both Twitter and blog variables to simultaneously evaluate their effects. In addition, there is scant research that evaluates the effect of valence and volume from two different communication channels at the same time (Seok, Lee, and Kim 2018).

The practical implications of this research are as follows: First, online WOM promotes sales. So far, numerous researches on the relationship between online WOM and temporary experience goods has been published, yet we found that research on the relationship between online WOM and durable goods is rare. In research that measures the effect of online WOM on the cell phone industry (Chung and Kim 2011), it was shown that online WOM affects the sales of durable goods positively. Therefore, firms selling durable goods may also make an attempt to increase their sales through managing and applying online WOM methods. Second, according to the characteristics of various communication channels, the effects of online WOM on sales differ. Although blogs and Twitter are both communication channels, they have different characteristics. While Twitter limits the number of words that can be used for each post and thus limits users from expressing detailed experience with certain products, blogs do not have such limits and therefore feature many posts that focus on sharing experiences (Wagner and Bolloju 2005). In other words, because communication channels have their own unique characteristics, companies can create strategies suitable to their targeted communication channels.

\subsection{Limitation and Future Studies}

Despite making various contributions, this paper also has several limitations. First, the subject of this research is limited to the automobile industry. Because most research that has studied online WOM has gathered data on temporary experience goods, such as books and movies, we chose to focus on the automobile industry to overcome such limitations. However, this research by itself does not ensure a generalization of our conclusion. Therefore, more research on not only durable goods but 
also other types of goods to generalize the effect of online WOM is required. Second, this study gathers data only from the Korean market. Because of this restriction, we cannot fully exclude the possibility that the conclusion is derived partially from characteristics of Korean consumers. Therefore, future research on the same subject yet with different sets of data is required to overcome this limitation and provide new insight. Thirdly, we did not consider traditional marketing factors, such as advertising expenditures. Although we already knew of such limitations and thus made an attempt to gather data on marketing variables, we could not do so because companies did not provide us with access to their data. Therefore, we believe that more meaningful implications can be found if more data, such as marketing expenses, were made available. Lastly, examining the relationship between volume and valence such as interaction effect can contribute to generalization of the effect of online WOM. Even though our research does not deal with the interaction effect since it is not our main interest, if the interaction effect is positive and significant, one can conclude that influence of volume of online WOM on sales gets stronger when valence increases. Therefore, study on such relationship between volume and valence would be another interesting issue regarding online WOM.

〈Received March 25. 2019〉

〈Accepted July 22. 2019〉

\section{References}

Aydin, M., \& Malcioglu, G. (2016). Financial development and economic growth relationship: The case of OECD countries. Journal of Applied Research in Finance and Economics, 2(1), 1-7.

Babić Rosario, A., Sotgiu, F., De Valck, K., \& Bijmolt, T. H. (2016). The effect of electronic word of mouth on sales: A meta-analytic review of platform, product, and metric factors. Journal of Marketing Research, 53(3), 297-318.

Baker, A. M., Donthu, N., \& Kumar, V. (2016). Investigating how word-of-mouth conversations about brands influence purchase and retransmission intentions. Journal of Marketing Research, 53(2), 225-239.

Banerjee, A. V. (1992). A simple model of herd behavior. The Quarterly Journal of Economics, 107(3), 797-817.

Breusch, T. S., \& Pagan, A. R. (1980). The Lagrange multiplier test and its applications to model specification in econometrics. The Review of Economic Studies, 47(1), 239253.

Chen, Y., Wang, Q., \&Xie, J. (2011). Online social interactions: A natural experiment on word of mouth versus observational learning. Journal of Marketing Research, 48(2), 238-254.

Chevalier, J. A., \& Mayzlin, D. (2006). The 
effect of word of mouth on sales: Online book reviews. Journal of Marketing Research, 43(3), 345-354.

Chi, H. K., Yeh, H. R., \& Yang, Y. T. (2009). The impact of brand awareness on consumer purchase intention: The mediating effect of perceived quality and brand loyalty. the Journal of International Management Studies, 4(1), 135-144

Chintagunta, P. K., Gopinath, S., \& Venkataraman, S. (2010). The effects of online user reviews on movie box office performance: Accounting for sequential rollout and aggregation across local markets. Marketing Science, 29(5), 944-957.

Chung, J. H., \& Kim, K. H., (2011). The change of dynamic interaction between online buzz activities and sales over time. Journal of Korean Marketing Association, 26(3), 85-109.

Cox, J. L., Martinez, E. R., \& Quinlan, K. B. (2008). Blogs and the corporation: managing the risk, reaping the benefits. Journal of Business Strategy, 29(3), 4-12.

Cui, G., Lui, H. K., \& Guo, X. (2012). The effect of online consumer reviews on new product sales. International Journal of Electronic Commerce, 17(1), 39-58.

Doh, S. J., \& Hwang, J. S. (2009). How consumers evaluate eWOM (electronic word-of-mouth) messages. CyberPsychology \&Behavior, 12(2), 193-197.

Dewan, S., \& Ramprasad, J. (2009). Chicken and egg? Interplay between music blog buzz and album sales, PACIS 2009 Proceedings, 87.

Duan, W., Gu, B., \& Whinston, A. B. (2008). The dynamics of online word-of-mouth and product sales - An empirical investigation of the movie industry. Journal of Retailing, 84(2), 233-242.

Dumitrescu, E. I., \& Hurlin, C. (2012). Testing for Granger non-causality in heterogeneous panels. Economic Modeling, 29(4), 1450-1460.

File, K. M., \& Prince, R. A. (1992). Positive word-of-mouth: customer satisfaction and buyer behaviour. International Journal of Bank Marketing, 10(1), 25-29.

Gopinath, S., Thomas, J. S., \& Krishnamurthi, L. (2014). Investigating the relationship between the content of online word of mouth, advertising, and brand performance. Marketing Science, 33(2), 241-258.

Granger, C. W. (1969). Investigating causal relations by econometric models and cross $^{-}$ spectral methods. Econometrica: Journal of the Econometric Society, 424-438.

Hausman, J. A. (1978). Specification tests in econometrics. Econometrica: Journal of the Econometric Society, 1251-1271.

Hennig-Thurau, T., Wiertz, C., \& Feldhaus, F. (2015). Does Twitter matter? The impact of microblogging word of mouth on consumers' adoption of new movies. Journal of the Academy of Marketing Science, 43(3), 375-394. 
Hennig-Thurau, T., Walsh, G., \& Walsh, G. (2003). Electronic word-of-mouth: Motives for and consequences of reading customer articulations on the Internet. International Journal of Electronic Commerce, 8(2), 51-74. Jansen, B. J., Zhang, M., Sobel, K., \& Chowdury, A. (2009). Twitter power: Tweets as electronic word of mouth. Journal of the American Society for Information Science and Technology, 60(11), 2169-2188.

Jin, S. A. A., \& Phua, J. (2014). Following celebrities' tweets about brands: The impact of twitter-based electronic word-of-mouth on consumers' source credibility perception, buying intention, and social identification with celebrities. Journal of Advertising, 43 (2), 181-195.

Johnson, T. J., \& Kaye, B. K. (2004). Wag the blog: How reliance on traditional media and the Internet influence credibility perceptions of weblogs among blog users. Journalism \&Mass Communication Quarterly, 81(3), 622-642.

Kaplan, A. M., \& Haenlein, M. (2011). Two hearts in three-quarter time: How to waltz the social media/viral marketing dance. Business Horizons, 54(3), 253-263.

Kim, K. S. (2010). Web WOM Effect of Blog to The 20s Young Generation in The Process of Restaurant Choice: Focused on Outback Blog of NAVER. Journal of Tourism and Leisure Research, 22(1), 113131.
Lee, M. K., Cheung, C. M., Lim, K. H., \& Ling Sia, C. (2006). Understanding customer knowledge sharing in web-based discussion boards: An exploratory study. Internet Research, 16(3), 289-303.

Lee, M., \& Youn, S. (2009). Electronic word of mouth (eWOM) How eWOM platforms influence consumer product judgement. International Journal of Advertising, 28(3), 473-499.

Lin, C., Wu, Y. S., \& Chen, J. C. V. (2013). Electronic word-of-mouth: The moderating roles of product involvement and brand image. TIIM 2013 Proceedings, 39-47.

Liu, Y. (2006). Word of mouth for movies: Its dynamics and impact on box office revenue. Journal of Marketing, 70(3), 74-89.

Lopez, L., \& Weber, S. (2018). Testing for Granger causality in panel data. The Stata Journal, 17(4), 972-984.

Luo, X. (2009). Quantifying the long-term impact of negative word of mouth on cash flows and stock prices. Marketing Science, 28(1), 148-165.

Min. I. S., \& Choi, P. (2016). STATA Paneldata Analysis. Seoul, Jiphilmedia

Moorman, Christine (2014), "CMO Survey Report: Highlights and Insights," (August), (accessed January 7, 2015), available at: http://cmosurvey.org/files/2014/09/The _CMO_SurveyHighlights_and_Insights -Aug-2014.pdf

Nielsen (2009) "Global advertising consumers 
trust real friends and virtual strangers the most”. Newswire (blog), July 7, [available at: https://www.nielsen.com/us/en/insights /news/2009/global-advertising-consumers -trust-real-friends-and-virtual-strangers -the-most.html]

Nielsen (2012) How connectivity influences global shopping. Newswire (blog), August 28, [available at: https://www.nielsen. com/us/en/insights/news/2012/howconnectivity-influences-global-shopping. html]

Ogut, H., \& Onur Tas, B. K. (2012). The influence of internet customer reviews on the online sales and prices in hotel industry. The Service Industries Journal, 32(2), 197-214.

Pal, S. K., \&Kapur, V. (2010). Blog marketing strategies for mature and emerging markets. International Journal of Innovation, Management and Technology, 1(4), 411. Pan, B., MacLaurin, T., \&Crotts, J. C. (2007). Travel blogs and the implications for destination marketing. Journal of Travel Research, 46(1), 35-45.

Park, J., Gu, B., \&Lee, H. (2012). The relationship between retailer-hosted and third-party hosted WOM sources and their influence on retailer sales. Electronic Commerce Research and Applications, 11(3), 253-261.

Peng, J., Zhang, G., Zhang, S., Dai, X., \&Li, J. (2014). Effects of online advertising on automobile sales. Management Decision, 52(5), 834-851.
Qin, L. (2011). Word-of-blog for movies: A predictor and an outcome of box office revenue?. Journal of Electronic Commerce Research, 12(3), 187.

Ratchford, B. T., Talukdar, D., \&Lee, M. S. (2001). A model of consumer choice of the Internet as an information source. International Journal of Electronic Commerce, 5(3), 7-21.

Richins, M. L. (1983). Negative word-of-mouth by dissatisfied consumers: A pilot study. Journal of marketing, 47(1), 68-78.

Rui, H., Liu, Y., \&Whinston, A. B. (2010, December). Chatter Matters: How Twitter Can Open the Black Box of Online Wordof-Mouth. In ICIS (p. 204).

Seok, J., Lee, Y., \& Kim, B. D. (2018). Impact of Publicizing Corporate Social Responsibility on Brand Performance: The Moderating Effect of Brand Nationality. In 2018 Korea Marketing Conference, Korean Marketing Association, Busan, Korea (pp. 20-21).

Seok, J., Kim, B. D., \& Go, S. (2019). Impact of R\&D Investment on Firm Value: The Role of Customer Awareness. Journal of Korean Society of Consumer Studies, 30 (1), 43-67.

Seok, J., Lee, Y., \& Kim, B. D. (2018, July). Do Actions Speak Louder Than Words? The Power of Publicizing Corporate Social Responsibility. In 2018 Global Marketing Conference at Tokyo (pp. 435-435).

Seok, J., Lee, Y., GO, S., \& Kim, B. D. (2017). 
Impact of Publicizing Corporate Social Responsibility on Firm Value. Korean Management Review, 46(6), 1663-1688.

Servaes, H., \& Tamayo, A. (2013). The impact of corporate social responsibility on firm value: The role of customer awareness. Management Science, 59(5), 1045-1061.

Shah, S., Ahmed, A., \& Ahmad, N. (2013). Role of packaging in consumer buying behavior. International Review of Basic and Applied Sciences, 1(2), 35-41.

Sotiriadis, M. D., \& Van Zyl, C. (2013). Electronic word-of-mouth and online reviews in tourism services: the use of twitter by tourists. Electronic Commerce Research, 13(1), 103-124.

Statista (2017). "Number of social media users worldwide 2010-2021" (accessed March9, 2019), [Available at: https://www.statista. com/statistics/278414/number-of-worldwide -social-network-users]
Stauss, B. (1997). Global word of mouth: Service bashing on the internet is a thorny issue. Marketing Management, 6(3), 28-30

Wagner, C., \& Bolloju, N. (2005). Supporting knowledge management in organizations with conversational technologies: Discussion forums, weblogs, and wikis. Journal of Database Management, 16(2), I.

Wooldridge, Jeffrey M.(2016), Introductory econometrics: A modern approach 6th edition, Cengage Learning.

Yoo, C. J., Ahn, K. H., \& Park, S. W. (2011). A Study of the Influence of Online Wordof-Mouth on the Customer Purchase Intention. Asia Marketing Journal, 13(3), 209-231.

Yüksel, S. (2017). The impacts of research and development expenses on export and economic growth. International Business and Accounting Research Journal, 1(1), $1-8$. 